DOI: https://doi.org/10.24297/jap.v16i1.8274

\title{
MWCNTs/ZnO Nanofibers Fabrication, Properties and Applications
}

\author{
M. Dawy and Rabab Khaled \\ Department of Physical Chemistry, National Research Center, Giza, 12622, Egypt. \\ m_dawy9@yahoo.com
}

\begin{abstract}
Electrospun MWCNTs nanofibers (CNF1, CNF2 and CNF3) with different concentrations of MWCNTs $(0.3,1.5$, 2 wt\%), respectively, were deposited on Aluminum foil substrates. Also, Zinc Acetate dihydrate $\mathrm{Zn}(\mathrm{CH} 3 \mathrm{COO})_{2} \cdot 2 \mathrm{H}_{2} \mathrm{O}$ (ZNF) and MWCNTs/zinc acetate (CZNF) nanofibers were deposited on Aluminum foil substrates and annealed in the presence of oxygen at $400{ }^{\circ} \mathrm{C}$. The resultant fibers were characterized using $\mathrm{X}$ ray differaction (XRD), scanning electron microscope with energy dispersive $X$-Ray spectrophotometry (SEM, EDX), Fourier transform infrared (FTIR). SEM, EDX and FTIR exhibited a total decomposition of the organic precursor after calcination and formation of zinc oxide (ZONF and CZONF). The mean fiber diameter was found to be increased with increasing MWCNTs concentration and ranged 490-767 nm. XRD patterns indicated that $\mathrm{ZnO}$ was corundum with the hexagonal wurtzite structure. The crystallite size of ZONF and CZONF were determined by shurrer equation to be 26 and $29.7 \mathrm{~nm}$, respectively. The optical analysis indicated that the percentage transmittance increased after calcination.The band gap for the electrospun fibers before and after calcination was calculated. CZONF nanofibers have electrical properties similar to those of semiconductors. The tested compounds CNF2, CNF3, CZNF and CZONF exhibited different activities against the bacteria and yeast pathogen Candidaalbicans. CZNF compound is the most active against the bacteria and yeast pathogen. So, these compounds can be used as food packaging.
\end{abstract}

\section{Keywords}

MWCNTs/ZnO Nanofibers, electrical, optical and biological properties

\section{Introduction}

Carbon nanotubes (CNTs) have attracted considerable research interest in the last decade because of their unique optical, electronic, magnetic, mechanical, and gas adsorption properties. They have been regarded as promising candidates for versatile applications. Exhibiting high electrical conductivity and high electron storage capacity (one electron for every 32 carbon atoms) [1, 2], CNTs can act as extremely effective electron sinks. Hence, CNTs supported with metal oxide nanoparticles are expected to exhibit different physical properties from those of neat CNT.

Zinc oxide semiconductor materials have been widely used primarily due to low cost and outstanding chemical and physical properties [3]. $\mathrm{ZnO}$ is an $\mathrm{n}$-type material having a wide band gap (3.21-3.42 eV) at room temperature. It is a group II-VI compound semiconductor having a stable wurtzite structure and large excitation binding energy of $60 \mathrm{meV}$ with lattice spacing $a=0.325 \mathrm{~nm}$ and $c=0.521 \mathrm{~nm}$. It is a unique material that exhibits optical, semiconducting, pyroelectric and piezoelectric properties [4,5]. It has attracted serious research attention because of its applicability to wide applications such as light emitting diode, [6, 7], solar cells [8,9], chemical and gas sensors [10], ultraviolet (UV) light detector [11], stimulated emission with low loss and high gain [12], and transparent conducting oxide [13]. Due to these varied applications, several methods including thin films and polymeric approaches have been employed to deposit $\mathrm{ZnO}$. Some of the thin film methods used include; chemical vapour deposition [14,15,16], chemical bath deposition [17], laser deposition $[18,19]$. 
$\mathrm{ZnO}$ nanoparticles have exhibited a strong bacterial growth inhibiting character [20]. ZnO has also gathered significant attention due to its various applications such as UV light emitting diodes, laser diodes and catalysts [21]. ZnO is widely used to treat a variety of skin conditions, in products such as baby powder, barrier creams to treat diaper rashes and in Calamine lotion, antidandruff shampoos and antiseptic ointments [22]. Nano zinc is non-toxic, with wide band gap has also been identified as a promising semiconductor material for exhibiting ferromagnetism (RFTM) at room temperature when doped with most of the transition metal elements [23].

The electrospinning method dates back to the work of Zeleny in 1914 and was previously termed "electrostatic spinning". This researcher found the technique to be useful for spinning polymer fibers having a small diameter [24]. This method, which uses the principle of electrostatics depends on electromotive force to form a fiber. This method has also been described as indispensable in the scientific and economic resurgence for developing nations [25]. Electrospinning has continued to gain serious research attention owing to its unique properties of the resultant nano/micro fibres (large surface area to volume ratio and cost effectiveness) [26, 27]. ZnO nanofibres, including nanotube and nanorods [28] belong to the one-dimensional group of nanomaterials which are flexible in nature. $\mathrm{ZnO}$ nanofibres have demonstrated improved properties in photoconducting, semi-conducting and piezoelectric properties [29, 30\& 31].

In this study, we synthesized $\mathrm{ZnO}$ and $\mathrm{ZnO}$ /MWCNTs nanofibers by electrospinning technique. The fibers have been characterized for morphology, composition, structure and further investigated for the antibacterial properties with respect to their crystallite size. Also, dielectric constant and conductivity will be studied. The nanofiber Such a material was designed and synthesized with a view to electronic and biological applications.

\section{Materials and Methods}

MWCNT, nitric acid (68\% conc), ethanol, Poly(vinyl Alchol) ( $\mathrm{Mw}=125,000 \mathrm{~g}$ by GPC), zinc acetate dihydrate $\left(\mathrm{Zn}(\mathrm{CH} 3 \mathrm{COO})_{2} \cdot 2 \mathrm{H}_{2} \mathrm{O}\right)$ salt $\geq 99 \%$ assay from Sigma-Aldrich.

\section{Experimental}

\section{Modification of MWCNT:}

$0.5 \mathrm{gm}$ of MWCNT was dissolved in $63 \mathrm{ml}$ nitric acid (68\% conc) and completed with distilled water till $100 \mathrm{ml}$. The solution was refluxed for $20 \mathrm{~h}$ and $100^{\circ} \mathrm{C}$. The precipitate was washed with ethanol and distilled water several times up to $\mathrm{pH}$ value of 7 and was dried at $70^{\circ} \mathrm{C}$.

Preparation of MWCNTnanofibers:

Different weight percent of MWCNT $(0.3,1.5,2$ wt\%) was dissolved in ethanol and sonicated for $1 \mathrm{~h}$, then different weight percent of PVA (13 and $20 \mathrm{wt} \%$ ) (dissolved in distilled $\mathrm{H} 2 \mathrm{O}$ at $50-60{ }^{\circ} \mathrm{C}$ ) was added and stirring for $30 \mathrm{~min}$. The prepared solution was fed into the spinneret. The distance between the tip of the spinneret and the substrate was kept at $12 \mathrm{~cm} .16 \mathrm{kV}$ voltage was applied to the solution and the substrate attached to an aluminium foil was grounded. The produced nanofibers were put in the drier at $50^{\circ} \mathrm{C}$.

Preparation of $\mathrm{ZnO}_{2}$ nanofibers:

$10 \mathrm{wt} \%$ zinc acetate was dissolved in ditilled $\mathrm{H}_{2} \mathrm{O}$, then $30 \mathrm{wt} \%$ PVA was added and stirring for 30 min. The prepared solution was fed into the spinneret. The distance between the tip of the spinneret and the substrate was kept at $12 \mathrm{~cm}$. $16 \mathrm{kV}$ voltage was applied to the solution and the substrate attached to an aluminium foil was grounded. The produced nanofibers were put in the drier at $50{ }^{\circ} \mathrm{C}$. The deposited fibres were calcined at $400^{\circ} \mathrm{C}$ in furnace in the presence of oxygen for $4 \mathrm{~h}$. 
Preparation of MWCNT $-\mathrm{ZnO}_{2}$ nanofibers:

$0.5 \mathrm{wt} \%$ MWCNT was dissolved in ethanol and sonication for $2 \mathrm{~h}$, then $10 \mathrm{wt} \%$ zinc acetate (dissolved in distilled $\mathrm{H}_{2} \mathrm{O}$ ) was added and stirring for 30 min. Finally, 20wt\% PVA was added and stirring for 30 min. The prepared solution was fed into the spinneret. The distance between the tip of the spinneret and the substrate was kept at $12 \mathrm{~cm} .16 \mathrm{kV}$ voltage was applied to the solution and the substrate attached to an aluminium foil was grounded. The produced nanofibers were put in the drier at $50{ }^{\circ} \mathrm{C}$. The deposited fibres were calcined at $400^{\circ} \mathrm{C}$ in furnace in the presence of oxygen for $4 \mathrm{~h}[32]$.

Table 1: The codes of the prepared samples

\begin{tabular}{|l|c|c|c|}
\hline \multicolumn{1}{|c|}{ Code } & MWCNTs & $\begin{array}{c}\text { Zinc } \\
\text { acetate }\end{array}$ & PVA \\
\hline MWCNTs nanofibers 1 (CNF1) & $0.3 \mathrm{wt} \%$ & - & $13 \mathrm{wt} \%$ \\
\hline MWCNTs nanofibers 2 (CNF2) & $1.5 \mathrm{wt} \%$ & - & $20 \mathrm{wt} \%$ \\
\hline MWCNTs nanofibers 3 (CNF3) & $2 \mathrm{wt} \%$ & - & $20 \mathrm{wt} \%$ \\
\hline Zinc acetate nanofibers (ZNF) & - & $10 \mathrm{wt} \%$ & $30 \mathrm{wt} \%$ \\
\hline $\begin{array}{l}\text { Zinc oxide nanofibers after calcination } \\
\text { of ZNF (ZONF) }\end{array}$ & - & - & - \\
\hline $\begin{array}{l}\text { MWCNTs-zinc acetate nanofibers (CZNF) } \\
\text { MWCNTs-zinc oxide nanofibers after } \\
\text { calcination of CZNF (CZONF) }\end{array}$ & $0.5 \mathrm{wt} \%$ & $10 \mathrm{wt} \%$ & $20 \mathrm{wt} \%$ \\
\hline
\end{tabular}

\section{Antimicrobial Assay}

The antimicrobial activities of samples were determined by the agar diffusion technique [33]. Sterile nutrient and Czapek'sdox agar media were inoculated, separately, with $100 \mu \mathrm{l}$ cell suspension of the tested bacteria and yeast poured into Petri-dishes (15 cm diameter). Each sample was dissolved in dimethyl sulfoxide (DMSO) with concentration $(10 \mathrm{mg} / \mathrm{ml}), 50 \mu \mathrm{l}$ from each sample was bearing on filter paper disc $(1 \mathrm{~cm}$ diameter). Solvent was allowed to evaporate and the discs were deposited on the surface of inoculated agar plates and kept at low temperature before incubation which favors diffusion over microbial growth to detect the inhibition zone clearly. The plates were incubated at $35^{\circ} \mathrm{C}$ for bacteria and at $30^{\circ} \mathrm{C}$ for yeast. The antimicrobial activity was expressed as the diameter of inhibition zone in $\mathrm{mm}$ and compared with the antibiotic amoxicillin trihydrate.

\section{Measurements:}

The as-spun and calcined fibres were analysed for their chemical, structural, optical and electrical properties. Scanning electron microscopy (SEM) observations were carried out using a QUANTA FEG250 field emission scanning electron microscope. X-ray diffraction (XRD) measurements were performed using Philips PW 1710 diffractometer with $\mathrm{Cu} \mathrm{K}$ radiation. The energy dispersive $\mathrm{X}$-ray (EDAX) analysis provides a way of analysing the chemical composition of the prepared materials. Dielectric parameters were recorded in the frequency range (100 HZ-5 MHZ) using HIOKI Japan 3532-50 LCR HI TESTER. 


\section{Results and Discussion:}

\subsection{XRD analysis:}

XRD patterns of as-prepared nanofibers samples were studied to investigate its crystal structure. Fig. 1 showed the XRD patterns of ZNF and CZNF. ZNF exhibited lower intensity peaks due to lower crystalinty since the material is amorphous. Whereas in CZNF, the distributions of prominent diffraction peaks matched well with rombohedral structure of graphite structure derived from [34].

It can be noticed that, XRD patterns (Fig.2) of ZONF and CZONF exhibited polycrystalline nature consisting of several diffraction peaks of hexagonal wurtzite structure with major five diffraction peaks at $2 \theta=31.85^{\circ}, 34.52^{\circ}$, $36.37^{\circ}, 47.52^{\circ}$ and $56.69^{\circ}$, respectively, pertaining to (100), (002), (101), (102) and (110) planes of ZnO. All diffraction peaks are in good agreement with those of the structure of ZnO (JCPDS card 96-230-0113) [34]. The unit cell parameters of the $\mathrm{ZnO}$ were found to be $\mathrm{a}=3.2494 \AA$ and $\mathrm{c}=5.2054 \AA$ [35]. The appearance of the characteristic $\mathrm{ZnO}$ peak pattern clearly showed that PVA is decomposed and the nanofibers are composed of ZnO. XRD pattern of CZONF showed broadening of the peaks and this confirmed that the composite contains MWCNTs. The average crystallite size of ZONF and CZONF calculated using the Debye-Scherrer equation:

$$
d=k \lambda / \beta \cos \theta
$$

where $d$ is the average crystal size of particles, $k$ is the Debye-Scherrer constant $(0.9), \lambda$ is the Xray wavelength $(0.15406 \mathrm{~nm}), \beta$ is the line broadening in a radian obtained from the full width at half maximum, and $\theta$ is the Bragg angle. The average crystal size of ZONF and CZONF were found to be 26 and $29.7 \mathrm{~nm}$, respectively.

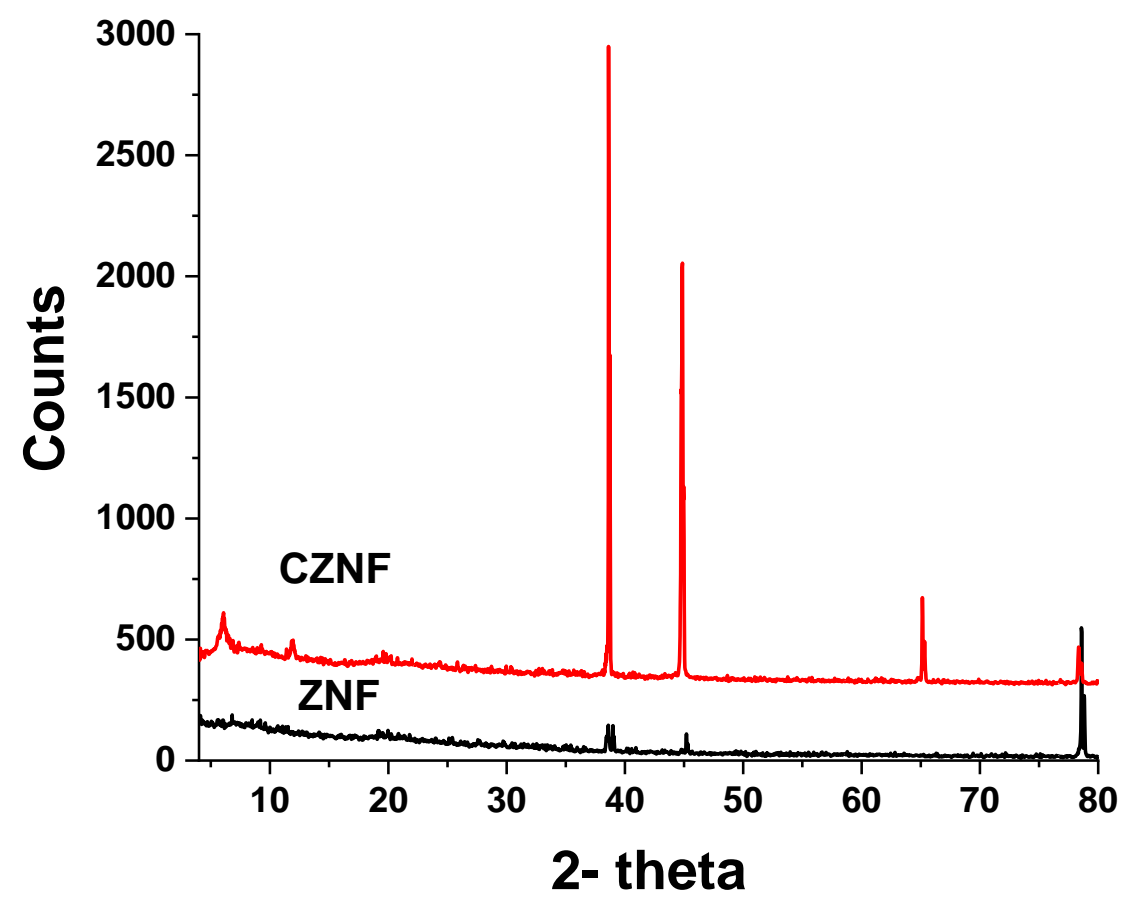

Fig.1: XRD patterns of zinc acetate nanofibers (ZNF) and MWCNTs-zinc acetate nanofibers (CZNF). 


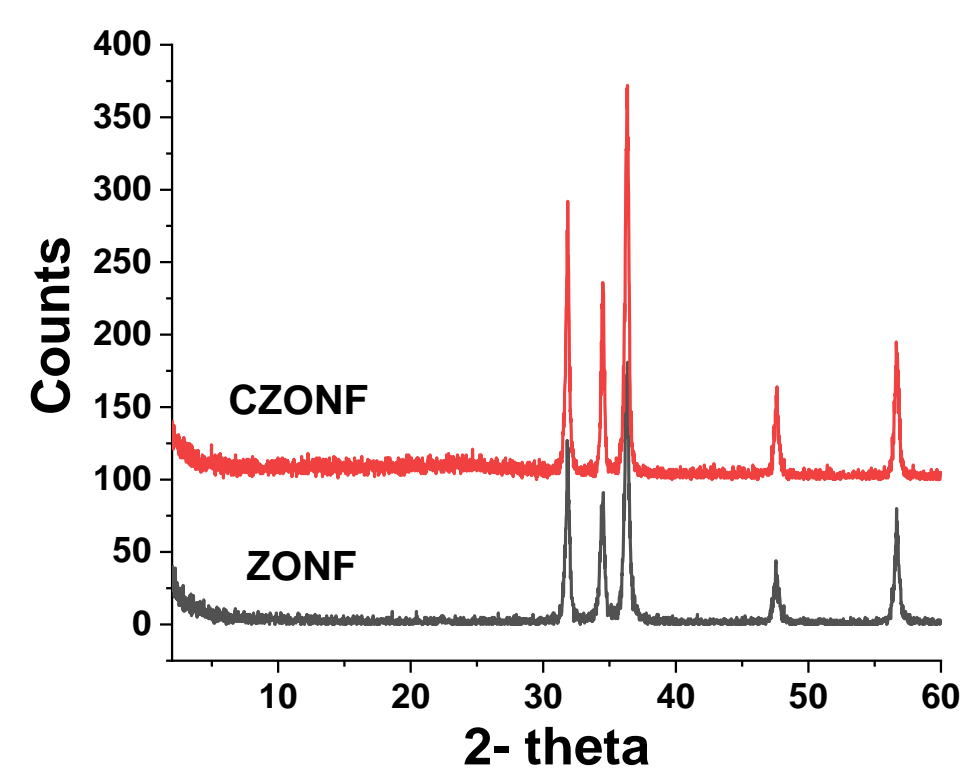

Fig.2: XRD patterns of zinc oxide nanofibers (ZONF) and MWCNTs-zinc oxide nanofibers (CZONF) after calcination.

\subsection{SEM:}

Fig.3. showed SEM images of CNF1, CNF2, CNF3, ZNF and CZNF. The average fiber diameter was found to be increased from 490 to $767 \mathrm{~nm}$ with increasing the concentration of MWCNTs.

SEM images of ZONF and CZONF after calcination were shown in Fig.4. It can be noticed that, the deposited nanofibers were non-woven in nature and are bead free. The difference in the measured mean fiber diameter observed in the as-spun and calcined materials could be attributed to the removal of PVA which served as a carrier for the metal oxide and other volatile organic constituents, such as acetate, during the calcination process. The EDX analysis of the calcined CZONF was shown in Fig.5 and Table 2. It is evident from the spectra that the fibers contained the desired elements: Zn $68.54 \%, 0$

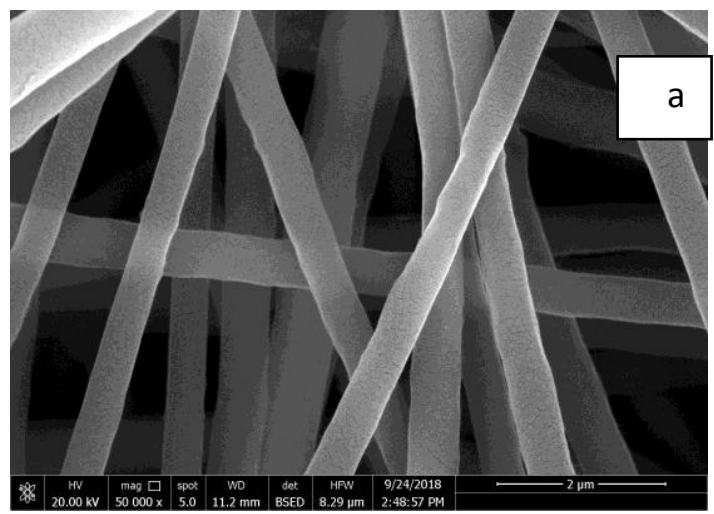
$22.12 \%$ and C $9.34 \%$.

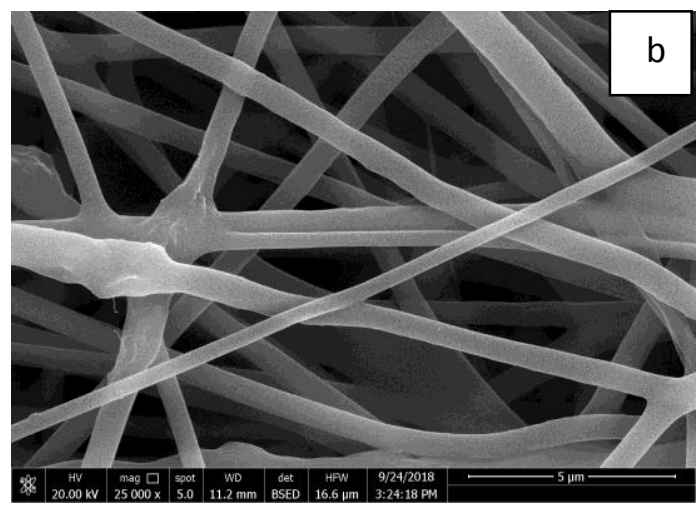



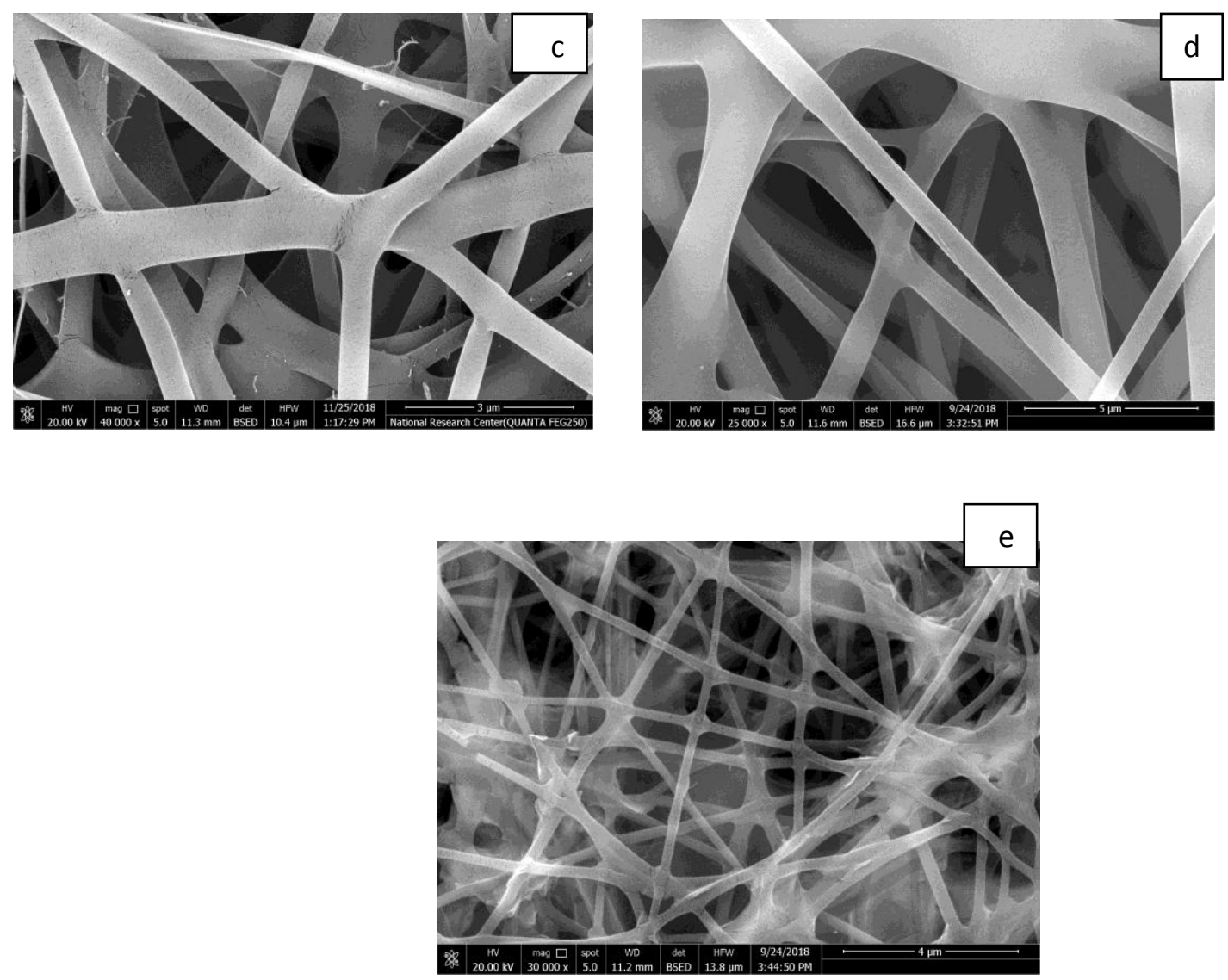

Fig.3: SEM images of (a) MWCNTs nanofibers (CNF1), (b) CNF2, (c) CNF3, (d) Zinc acetate nanofibers (ZNF), (e) MWCNTs-zinc acetate nanofibers (CZNF).
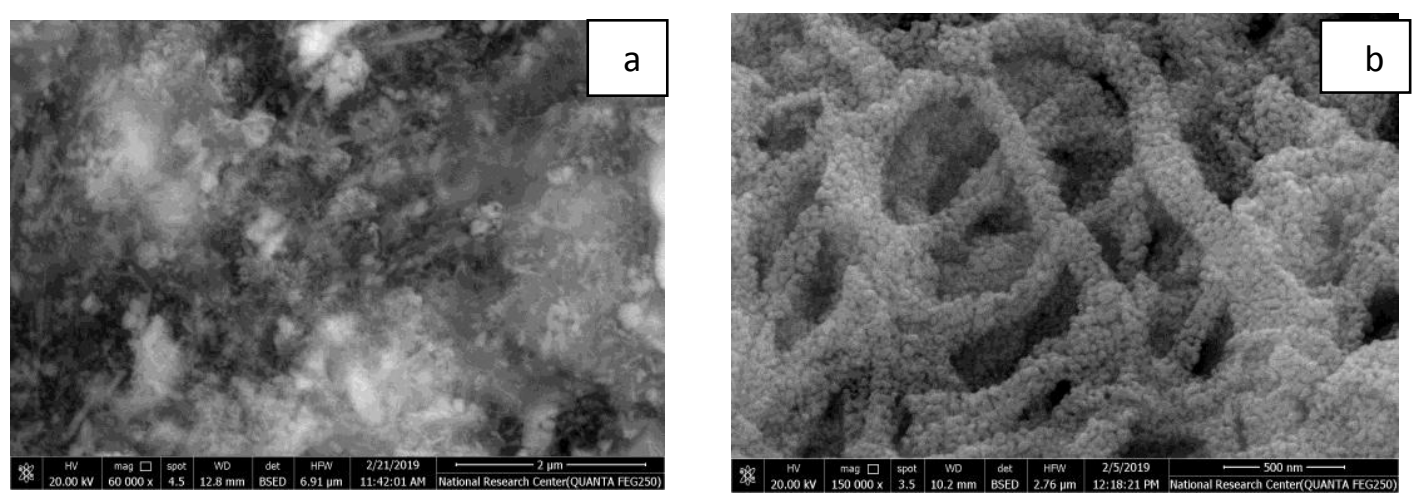

Fig.4: SEM images of (a) Zinc oxide nanofibers (ZONF) and (b) MWCNTs-zinc oxide nanofibers (CZONF) after calcination. 


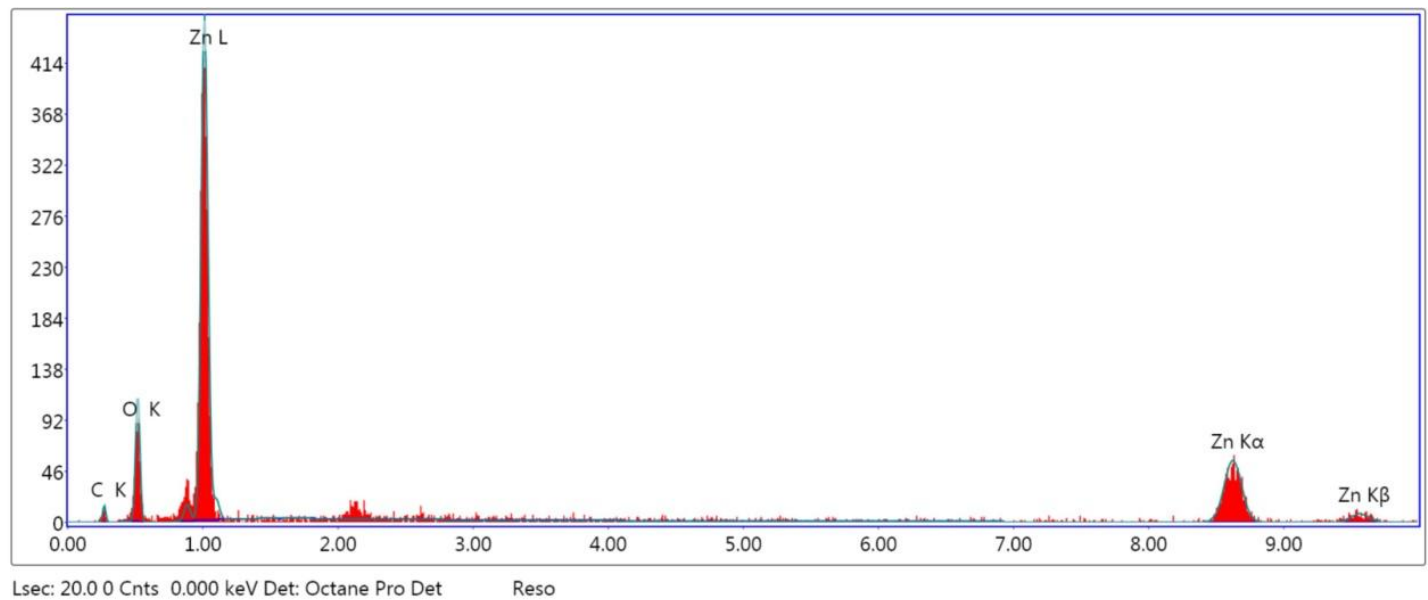

Atomic

Element Weight \% $\% \quad$ Net Int. Error \%

\begin{tabular}{l|llll}
\hline C K & 9.34 & 24.24 & 2.19 & 29.11 \\
\hline O K & 22.12 & 43.09 & 21.72 & 13.6 \\
\hline ZnK & 68.54 & 32.67 & 42.85 & 7.38
\end{tabular}

Fig.5 and Table 2: Elemental composition of MWCNTs-zinc oxide nanofibers (CZONF) determined by EDAX

\subsection{FT-IR}

FT-IR examination was performed in the range $400-4000 \mathrm{~cm}^{-1}$ of the prepared samples to examine the detailed structure of the bonding. FT- IR spectra of different concentrations of MWCNTs. It can be seen that the intensity of the peaks increased with concentration of MWCNTs (Fig.6). However, after the MWCNTs are treated, many groups are introduced onto the surface of MWCNTs, such as carbonyl groups reveal at about $1705 \mathrm{~cm}^{-1}$, and oxygen-hydrogen bonds and $\mathrm{C}=\mathrm{C}$ bonds reveal at about $3427 \mathrm{~cm}^{-1}$ and $1568 \mathrm{~cm}^{-1}$, respectively [ 36 ].

Fig.7 showed the FT-IR spectra of ZONF and CZONF calcined nanofibers. All the described peaks are weakened in the calcined $\mathrm{ZnO}$ nnanofibers. Also, the calcined IR spectra showed a well defined peak of $\mathrm{ZnO}$ at $426 \mathrm{~cm}^{-1}$, confirming the presence of $\mathrm{ZnO}$ and the decomposition of the PVA. Our results are in good agreement with the reported studies [37]. 


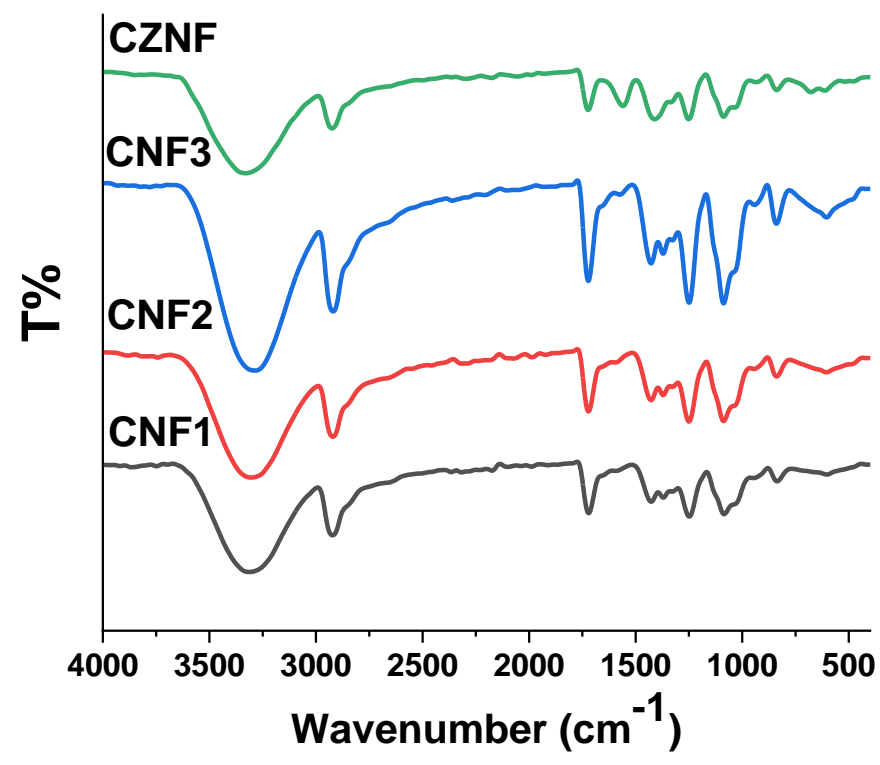

Fig.6: FT-IR spectra of MWCNTs nanofibers (CNF1), (CNF2), (CNF3) and MWCNTs-zinc acetate nanofibers (CZNF).

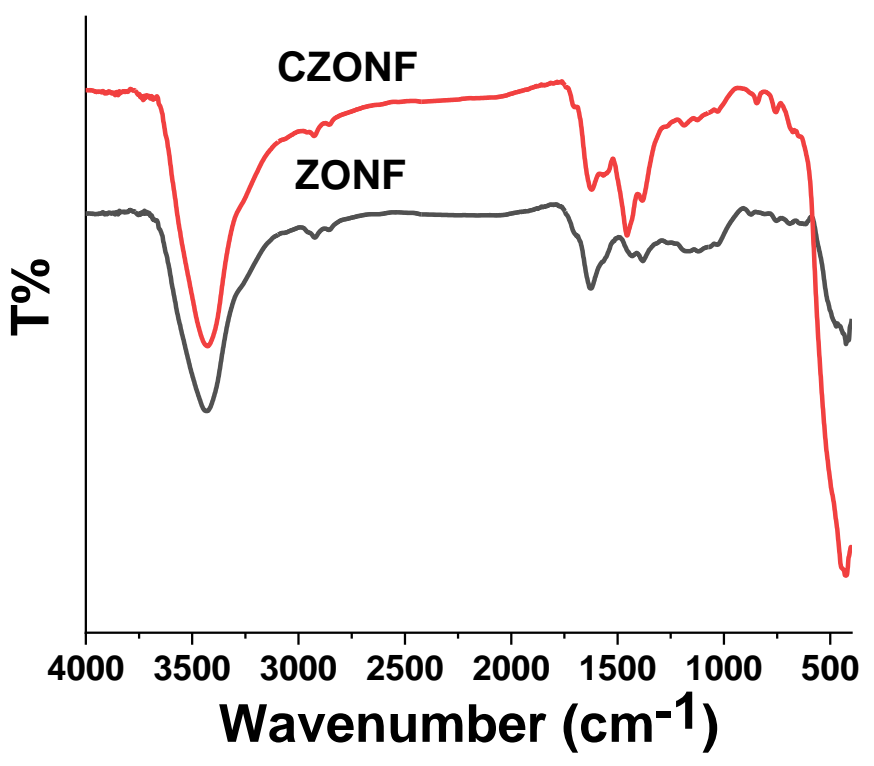

Fig.7: FT-IR spectra of zinc oxide nanofibers (ZNF) and MWCNTs-zinc oxide nanofibers (CZONF) after calcination.

\section{Optical characterization:}

UV-VIS transmition:

An increase in the percent of transmittance was observed in Fig. 8 with increasing MWCNTs percent in the samples CNF1, CNF2 and CNF3 nanofibers. It can also be observed that the MWCNTs addition has a profound effect on the fiber's optical transparency; with increase in transparency down to $65 \%$ and great increase due to 
the fact that the MWCNTs are not transparent and absorb the incoming light then increase the light scattering. Addition of $\mathrm{Zn}$ Acetate increased the transimition in visible region to $80 \%$ percent. This can be revealed that the $\mathrm{Zn}$-acetate fibers are highly transparent in the visible region from $600 \mathrm{~nm}$ about $95 \%$.

After calcination of CZNF, the optical transimittion increases for CZONF compound. This finding could be attributed to the decomposition of all the organic components presents in the as-spun fibres and the transformation from the amorphous state to crystalline state as evidenced by the XRD results. The percent transmittance for CZNF (80\%) was found to be lower than that of CZONF (90\%). As earlier stated; the decomposition of the organic polymer and the removal of the acetate from the $\mathrm{Zn}\left(\mathrm{CH}_{3} \mathrm{COO}\right)_{2} \cdot 2 \mathrm{H}_{2} \mathrm{O}$ to form crystalline $\mathrm{ZnO}$ provoked a reduction in the thickness which led to a rise in the transmittance $[38,39]$. The transmittance increased from the visible to the near-infrared region. A high transmittance value for zinc oxide was also reported previously, which implies that the $\mathrm{ZnO}$ deposited is very transparent as it allowed almost all the incident light to pass through it and absorbed very little as shown in Fig.9. The optical bandgap of the CZNF and CZONF was 1.56 and $2.75 \mathrm{eV}$ and after calcination determined by assuming that $\mathrm{ZnO}$ is a direct band gap semiconductor

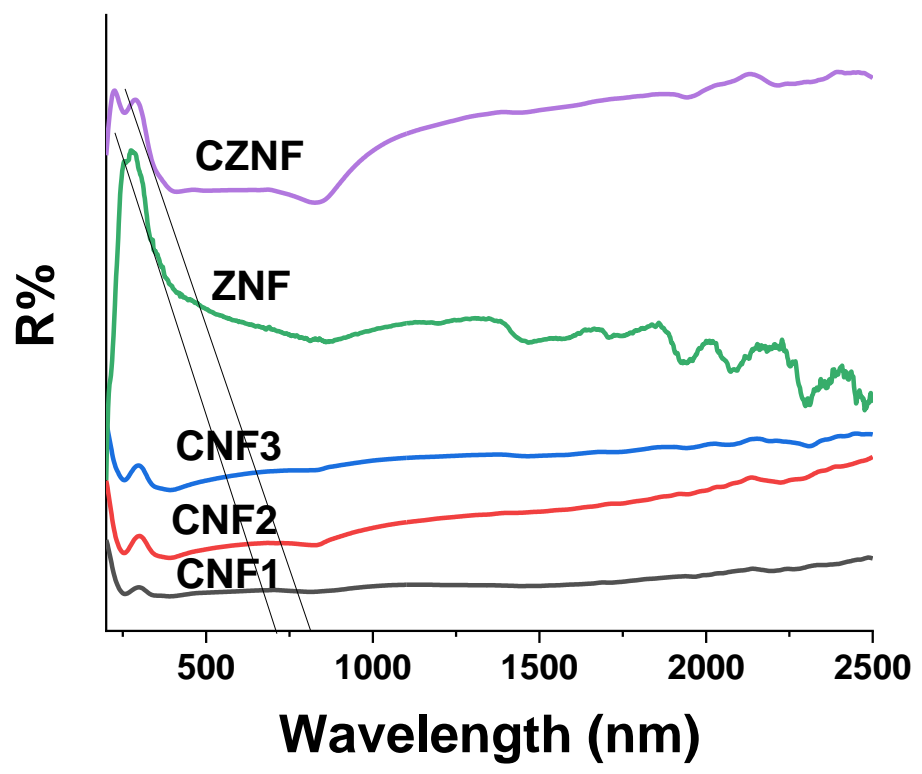

Fig.8: UV-VIS transimittion spectra of MWCNTs nanofibers, (CNF1), (CNF2), (CNF3) and MWCNTs/zinc acetate nanofibers (CZNF). 


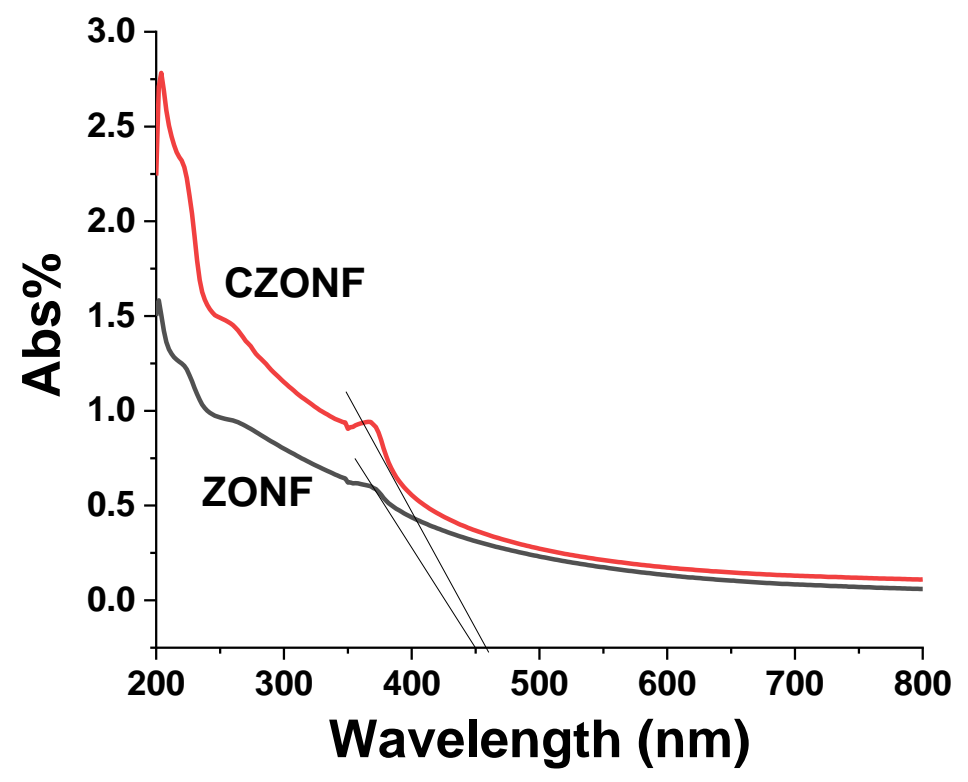

Fig.9: UV-VIS transimittion spectra of zinc oxide nanofibers (ZONF) and MWCNTs-zinc oxide nanofibers (CZONF) after calcination.

Table 3: the optical band gap of the samples

\begin{tabular}{|l|c|}
\hline Nanocomposites & The band gap (ev) \\
\hline ZNF & 1.78 \\
\hline CZNF & 1.56 \\
\hline ZONF & 2.81 \\
\hline CZONF & 2.75 \\
\hline
\end{tabular}

\section{Electrical Properties:}

The change of the electrical properties (dielectric constant and conductivity) of CNF1, CNF2, CNF3, ZNF and CZNF according to different frequency and concentration of MWCNT were studied (Figs. 10-13). The dielectric constant $(\dot{\varepsilon})$ of the MWCNTs nanofibers increased with increasing MWCNTs concentration whereas, ZNF is very low compared to that of CZNF individual MWCNTs.

The conductivity of ZNF is higher than that of CZNF, the reason for such low conductivity is that the presence of amorphous carbon and other impurities in MWCNTs prevents the flow of electrons [40-49]. One of the methods of improving the electrical properties of CNT fibers is to create a path through which electrons flow on the MWCNTs fibers $[44,45]$ succeeded in improving the electrical properties of MWCNT fibers via the synthesis of a metal-CNT composite fiber in a process called self-fuelled electrodeposition. Produced in such a way, the composite fibers were designed to serve as external circuits through which electrons could travel with a metal reductant deposited on the MWCNT surface. The electrical conductivity of CZNF nancomposite fibers improved that of MWCNTs . 


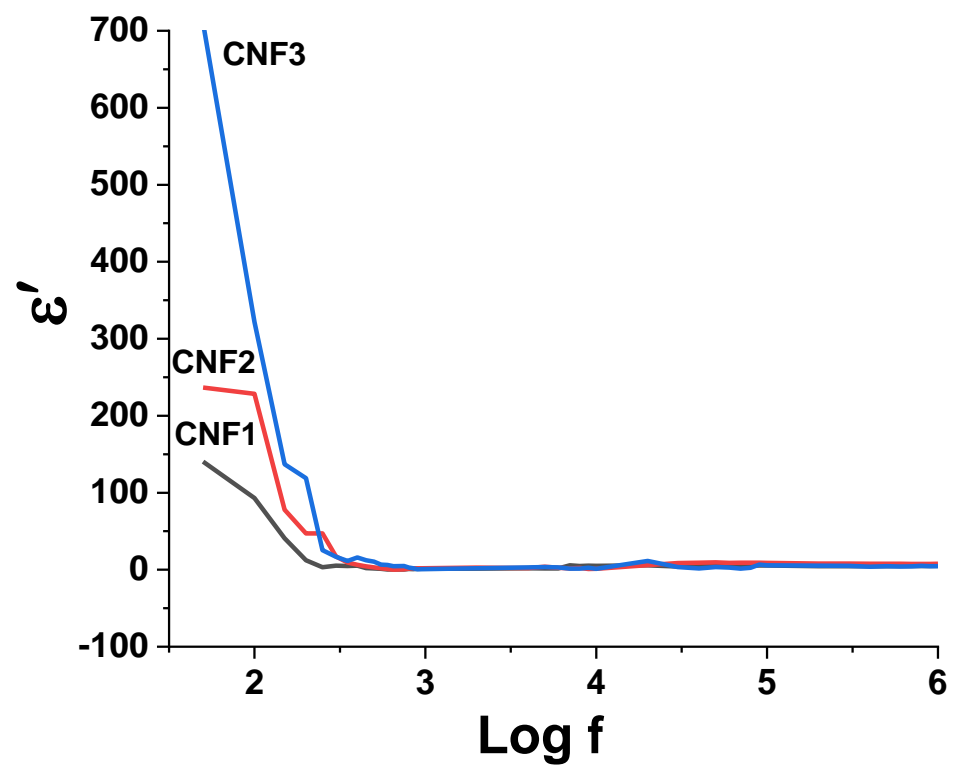

Fig.10: Variation of dielectric constant of MWCNTs nanofibers (CNF1), (CNF2) and (CNF3).

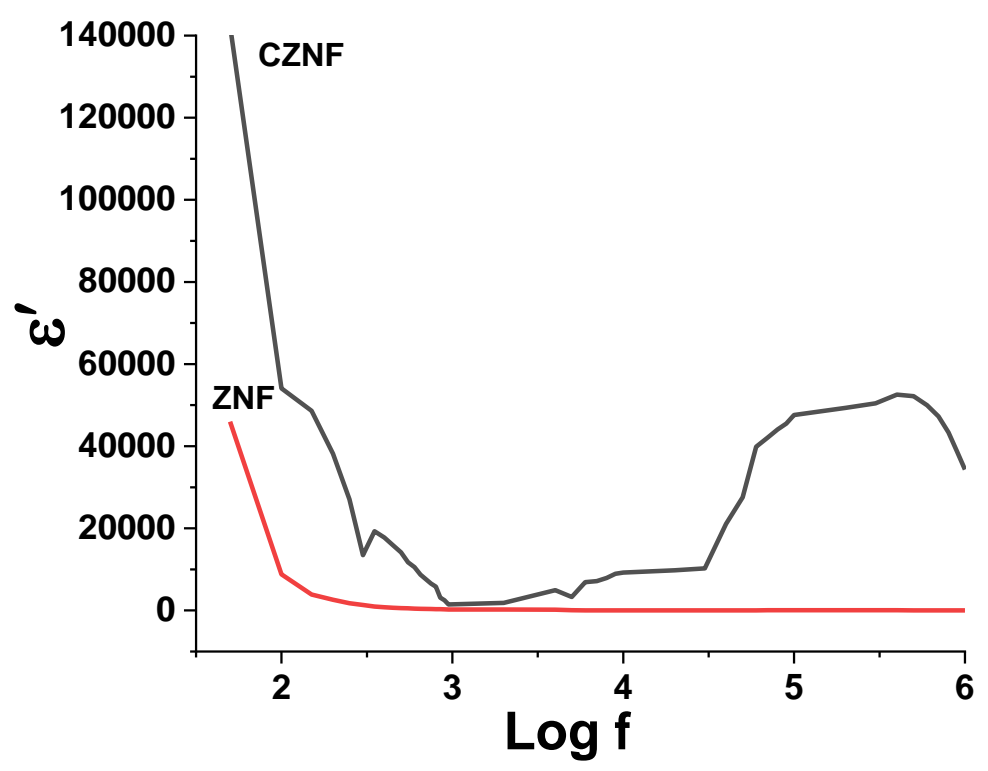

Fig.11: Variation of dielectric constant of zinc acetate nanofibers (ZNF) and MWCNTs-zinc acetate nanofibers (CZNF). 


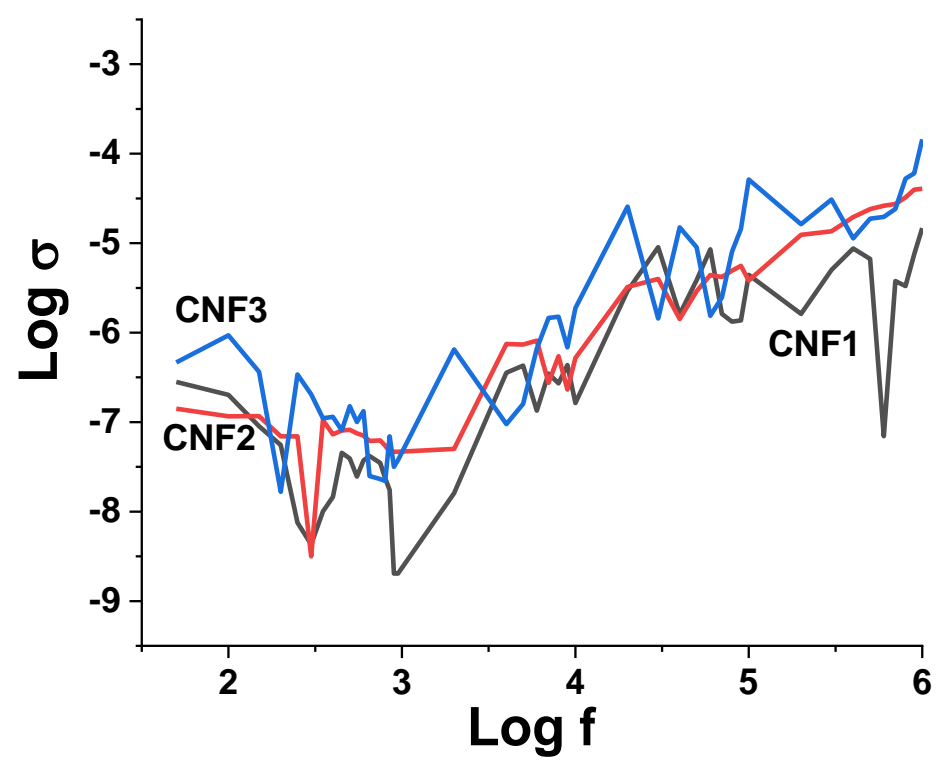

Fig.12: Variation of conductivity of MWCNTs nanofibers (CNF1), (CNF2) and (CNF3).

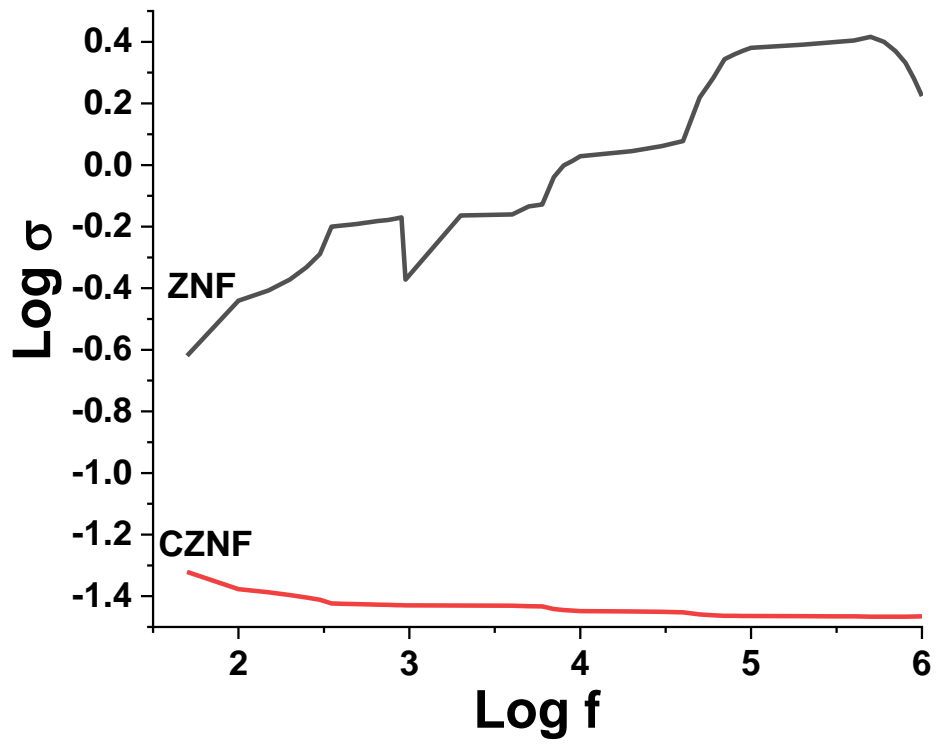

Fig.13: Variation of conductivity of zinc acetate nanofibers (ZNF) and MWCNTs-zinc acetate nanofibers (CZNF).

\section{Antimicrobial Activity}

As shown in table (3) Gram positive and negative bacteria were inhibited by compounds CNF2, CNF3, CZNF and CZONF. On the other hand, the tested compounds exhibited different activities against the yeast pathogen Candidaalbicans with compounds CNF2, CNF3, CZNF and CZONF. CZNF compound is the most 
active against the bacteria and yeast pathogen. So, these compounds can be used as food packaging, baby powder, barrier creams to treat diaper rashes, in Calamine lotion and antidandruff shampoo.

Table 4: Antimicrobial activity of some new compounds

\begin{tabular}{|l|l|l|l|l|l|l|l|l|l|}
\hline & $\begin{array}{l}\text { Gram } \\
\text { strain } \\
\text { reaction }\end{array}$ & CNF1 & CNF2 & CNF3 & CZNF & CZONF & ZONF & CONTROL & REFERANCE \\
Microorganism & (DEMSO) & & & & & & & & \\
\hline $\begin{array}{l}\text { Candida } \\
\text { albicans }\end{array}$ & & 15 & 15 & 18 & 30 & 25 & 0.12 & 15 & 40 \\
\hline $\begin{array}{l}\text { Bacillus cereus } \\
\text { Staphylococcus } \\
\text { aureus }\end{array}$ & Positive & 10 & 17 & 10 & 30 & 25 & 10 & 10 & 28 \\
\hline $\begin{array}{l}\text { E } \\
\text { Escherichia coli }\end{array}$ & Negative & 11 & 12 & 12 & 24 & 19 & 10 & 12 & 31 \\
\hline $\begin{array}{l}\text { Pseudomonas } \\
\text { aeruginosa }\end{array}$ & Negative & 11 & 19 & 11 & 25 & 20 & 0 & 12 & 27 \\
\hline
\end{tabular}

\section{Conclusions:}

MWCNTs and MWCNTs/ZnO composite nanofibers were successfully prepared by the electrospinning technique. The spun nanofibers were investigated including morphology, structure, chemical composition, bandgap and transmittance.The deposited nanofibers of $\mathrm{ZnO}$ has gained wide spread attention owing to its wide bandgap and high transmittance value. The UV peak at about $300 \mathrm{~nm}$ comes from MWCNTs. The peaks at about $368 \mathrm{~nm}$ are assigned to UV emission originating from the wide band gap of $\mathrm{ZnO}$. The transmittance value of MWCNTs increased with the addition of $\mathrm{ZnO}$ from $56 \%$ and $99 \%$ in the visible region makes it a candidate for applications in the field of optoelectronics. Electrical properties results showed that the conductivity of ZNF is higher than CZNF, the reason for such low conductivity is that the presence of amorphous carbon and other impurities in MWCNTs prevents the flow of electrons. CZONF nanofibers have electrical properties similar to those of semiconductors and show an electrical conductivity of $5-6 \times 10^{2} \mathrm{~S} / \mathrm{cm}$ at room temperature. The synthesized nanofibres were studied for antimicrobial activities against the microorganisms. It was observed that the tested compounds CNF2, CNF3, CZNF and CZONF exhibited different activities against the bacteria and yeast pathogen. CZNF compound is the most active against the bacteria and yeast pathogen. So, these compounds can be used as food packaging. It may also be concluded from this study that such nanofibers may be used in pharmaceutical research in future.

\section{Acknowledgements}

The authors are thankful to National Research Centre for his fund. 


\section{REFERENCES}

[1] Kongkanand A, Kamat PV (2007) Electron storage in single wall carbon nanotubes. Fermi level equilibration in semiconductor-SWCNT suspensions. ACS Nano 1(1):13-21. doi:10.1021/nn700036f.

[2] Kongkanand A, Domy'Onguez RM, Kamat PV (2007) Single wall carbon nanotube scaffolds for photoelectrochemical solar cells: capture and transport of photogenerated electrons. Nano Lett 7(3):676-680. doi:10.1021/nl0627238.

[3] Feynman R. There's plenty of room at the bottom. J Sci. 1991;254:1300-1301.

[4] Sondi I, Salopek-Sondi B. Silver nanoparticles as antimicrobial agent: a case study on E. coli as a model for Gram-negative bacteria.J Colloid Interface Sci. 2004;275(1):177.

[5] Morones JR, Elechiguerra JL, Camacho A, et al. The bactericidal effect of silver nanoparticles. Nanotechnology. 2005;16(10):2346.

[6] Sawai J. Quantitative evaluation of antibacterial activities of metallic oxide powders ( $\mathrm{ZnO}, \mathrm{MgO}$ and $\mathrm{CaO}$ ) by conductimetric assay. J Microbial Method. 2003;54:177-182.

[7] Loan TT, Long NN, Ha LH. Photoluminescence properties of Co-doped ZnOnanorods synthesized by hydrothermal method. J Phys D Appl Phys. 2009;42:65412.

[8] Akhavan O, Ghaderi E. Enhancement of antibacterial properties of Ag nanorods by electric field. Sci Tech Adv Mater. 2009;10:015003-015007.

[9] Herng TS, Lau SP, Yu SF, et al. Magnetic anisotropy in the ferromagnetic Cu-doped ZnO nanoneedles. Appl PhysLett. 2007;90:032509.

[10] Zhong CJ, Mave MM. Coree Shell assembled nanoparticles as catalysts. Adv Mater. 2001;13(19):15071511.

[11] Liz-Marzan LM. Tailoring surface plasmons through the morphology and assembly of metal nanoparticles. Langmuir. 2006;22(1):32-41.

[12] Alammar T, Mudring AV. Facile preparation of Ag/ZnO nanoparticles via photoreduction. J Material Sci. 2009;44(12):3218-3222.

[13] Kawashita M, Tsuneyama S, Miyaji F, Kokubo T, Kozuka H, Yamamotto K. Antibacterial silver-containing silica glass prepared by sol-gel method. Biomaterials. 2000;21:393-398.

[14] Pal S, Tak YK, Song JM. Does the antibacterial activity of silver nanoparticles depend on the shape of the nanoparticle? A study of the Gram-negative bacterium Escherichia coli. J App Environ Microbiol. 2007;73(6):1712-1720.

[15] Lin W-C, Chen C-N, Tseng T-T, Wei M-H, Hsieh JH, Tseng WJ. Micellar layer-by-layer synthesis of TiO2/Ag hybrid :particles for bactericidal and photocatalytic activities. J Eur Ceram Soc. 2010;30:2849-2857.

[16] Kassaee MZ, Akhavan A, Sheikh N, Sodagar A. Antibacterial effects of a new dental acrylic. J ApplPolym Sci. 2008;110:1699.

[17] Lee HJ, Yeo SY, Jeong SH. Antibacterial effect of nanosized silver colloidal solution on textile fabrics. J Mater Sci.2003;38:2199-2204. 
[18] Staumal B, Baretjky B, Mazilkin A, Protasiba S, Petrastrumal A. Increase of Mn solubility with decreasing grain size in ZnO. J Eur Ceram Soc. 2009;29:1963.

[19] Sawai J. Quantitative evaluation of antibacterial activities of metallic oxide powders ( $\mathrm{ZnO}, \mathrm{MgO}$ and $\mathrm{CaO}$ ) by conductimetric assay. J Microbial Method. 2003;54:177-182.

[20] Loan TT, Long NN, Ha LH. Photoluminescence properties of Co-doped ZnO nanorods synthesized by hydrothermal method. J Phys D Appl Phys. 2009;42:65412.

[21] Akhavan O, Ghaderi E. Enhancement of antibacterial properties of Ag nanorods by electric field. Sci Tech Adv Mater. 2009;10:015003-015007.

[22] Herng TS, Lau SP, Yu SF, et al. Magnetic anisotropy in the ferromagnetic Cu-doped ZnO nanoneedles. Appl PhysLett. 2007;90:032509.

[23] Zhong CJ, Mave MM. CoreeShell assembled nanoparticles as catalysts. Adv Mater. 2001;13(19):1507-1511.

[24] Liz-Marzan LM. Tailoring surface plasmons through the morphology and assembly of metal nanoparticles. Langmuir. 2006;22(1):32-41.

[25] E.D. Adelowo, A.Y. Fasasi, M.O. Adeoye, S.O. Alayande, Struc-tural and Optical Properties of Tin Doped Zinc Oxide Fibres Prepared By Electrospinning Technique, Chemistry and Materials Research (2013) 96-105.

[26] X. Zhang, M.R. Reagan, L.K. David, Electrospun Silk Bio-material Scaffolds for Regenerative Medicine, Advanced DrugDelivery Review (2009) 988-1006.

[27] J. -h. He, Y. Liu, ElectrospunNanofibres and Their Applications,iSmither, Shrewsbury, 2008.

[28] W.E. Teo, S. Ramakrishna, A review on electrospinningdesignandnanofibre assemblies, Nanotecnology (2006) R89-R106.

[29] N. Bhardwaj, S.C. Kundu, Electrospinning: A fascinatingfiber fabrication technique, Biotecnology Advances 28 (2010)325-347.

[30] S. Ramakrishna, K. Fujihara, W.-E. Teo, T.-C. Lim, Z. Ma, Anintroduction to electrospinning and nanofibers, World ScientificPublishing Company Limited, Singapore, 2005.

[31] B.M. Sorayani, R. Bagherzadeh, M. Latifi, Fabrication of com-posite PVDF-ZnOnanofiber mats by electrospinning for energyscavenging application with enhanced efficiency, J Polym Res 22(130) (2015).

[32] H.S Bolarinwa, M.U. Onuu, A.Y. Fasasi, S.O. Alayande, L.O. Animasahun, I.O. Abdulsalami, O.G. Fadodun, I.A. Egunjobi Determination of optical parameters of zinc oxide nanofibredeposited by electrospinning technique Journal of Taibah University for Science 11 (2017) 1245-1258.

[33] Wilkins, TD.,Holdeman, JJ., Abramson, IJ. and Moore, WEC. 1972. Standardized single-disc method for antibiotic susceptibility testing of anaerobic bacteria. Antimicrob Agents Chemother. I. 1(6):451-455.

[34] S. Martin, G. Liangfeng, T. Satyan, T. Satyanarayana, G. Feng,G. Marc, Simultaneous determination of several crystal structuresfrom powder mixtures: the combination of powder X-ray diffrac-tion, band-target entropy minimization and Rietveldmethods,Journal of Applied Crystallography 47 (2) (2014) 659-667.

[35] F .Avilés, J.V. Cauich- Rodríguez, L. Moo-Tah, A. May-Pat, \&R.Vargas-Coronado, 47(2009)2970-2975. 
[36] R. Yudianti, H. Onggo, Y. Saito, T. Iwata, and J.-I.Azuma. Open Materials Science Journal ,vol.5, (2011),pp.242-247.

[37] $\mathrm{Wu}, \mathrm{H} .$, Pan, W., 2006. Preparation of Zinc oxide nanofibers by electrospinning. J. Am. Ceram. Soc. 89, 699-701.

[38] Y.-Y. Cho, C. Kuo, Optical and electrical characterization of elec-trospun Al-doped zinc oxide nanofibers as transparent electrodes,J. Mater. Chem. C 4 (2016) 7649-7657.

[39] Y. Liao, T. Fukuda, S. Wang, Electrospun metal oxide nanofibersand their energy application, in: M.M. Rahman, M. Abdullah(Eds.), Nanofiber research - Reaching new heights, InTech Open,2016, pp. 169-190.

[40] Song SN, Wang XK, Chang RPH, Ketterson JB. Electronic properties of graphite nanotubules from galvanomagnetic effects. Phys Rev Lett, 72, 697 (1994). http://dx.doi.org/10.1103/PhysRevLett. 72.697.

[41] Bachtold A, Henny M, Terrier C, Strunk C, Schonenberger C, Salvetat JP, Bonard JM, Forro L. Contacting carbon nanotubesselectively with low-ohmic contacts for four-probe electric measurements. Appl Phys Lett, 73, 274 (1998). http://dx.doi.org/ 10.1063/1.121778.

[42] Dai H, Wong EW, Lieber CM. Probing electrical transport in nanomaterials: conductivity of individual carbon nanotubes. Science, 272, 523 (1996). http://dx.doi.org/10.1126/science.272.5261.523.

[43] Berger C, Yi Y, Wang ZL, de Heer WA. Multiwalled carbon nanotubes are ballistic conductors at room temperature. Appl Phys A, 74, 363 (2002). http://dx.doi.org/10.1007/s003390201279.

[44] Lee RS, Kim HJ, Fischer JE, Thess A, Smalley RE. Conductivity enhancement in single-walled carbon nanotube bundles doped with K and Br. Nature, 388, 255 (1997).

[45] Randeniya LK, Bendavid A, Martin PJ, Tran CD. Composite yarns of multiwalled carbon nanotubes with metallic electrical conductivity. Small, 6, 1806 (2010). http://dx.doi.org/10.1002/ smll.201000493. 